\title{
The Design of a Multi-Period and Multi-Echelon Perishable Goods Supply Network under Uncertainty
}

\author{
Ieva Meidute-Kavaliauskiene ${ }^{1, *(\mathbb{D})}$, Figen Y1ldırım ${ }^{2}$, Shahryar Ghorbani ${ }^{3}$ (i) and Renata Činčikaitè $^{1,4}$ \\ 1 Research Group on Logistics and Defence Technology Management, General Jonas Zemaitis Military \\ Academy of Lithuania, Silo 5a, 10322 Vilnius, Lithuania; renata.cincikaite@lka.lt \\ 2 Department of International Trade, Istanbul Commerce University, Istanbul 34445, Turkey; \\ figen@ticaret.edu.tr \\ 3 Department of Production Management, University of Sakarya, Sakarya 54050, Turkey; \\ d199004108@sakarya.edu.tr \\ 4 Business Management Faculty, Vilnius Gediminas Technical University, Saulètekio al. 11, \\ 10332 Vilnius, Lithuania \\ * Correspondence: ieva.meidute@lka.lt
}

check for

updates

Citation: Meidute-Kavaliauskiene, I.; Yıldırım, F.; Ghorbani, S.; Činčikaitè, R. The Design of a Multi-Period and Multi-Echelon Perishable Goods Supply Network under Uncertainty. Sustainability 2022, 14, 2472.

https://doi.org/10.3390/su14042472

Academic Editors: Surya

Prakash Singh, Ankur Chauhan and Harpreet Kaur

Received: 2 December 2021

Accepted: 18 February 2022

Published: 21 February 2022

Publisher's Note: MDPI stays neutral with regard to jurisdictional claims in published maps and institutional affiliations.

Copyright: () 2022 by the authors Licensee MDPI, Basel, Switzerland. This article is an open access article distributed under the terms and conditions of the Creative Commons Attribution (CC BY) license (https:// creativecommons.org/licenses/by/ $4.0 /)$.

\begin{abstract}
The value of superior supply network design is becoming increasingly important, especially in the perishable supply chain. Due to the recent developments in perishable products, perishable product supply chain (PPSC) management has attracted many researchers. The purpose of this study was to present a multi-period and multi-echelon perishable supply chain with regards to procurement time, cycle cost, and customer satisfaction. This study presented a new form of location-routing in a supply chain network for perishable products, accounting for environmental considerations, cost, procurement time, and customer satisfaction, such that the total costs, delivery time, and the emission of pollutants in the network were minimized while customer satisfaction was maximized. We formulated the problem as a multi-objective, nonlinear, mixed-integer program and the hybrid approach was proposed to solve the model. The mean error of the proposed algorithm for the objective function compared to the exact method in solving the sample problems was less than $3.4 \%$. The computational results revealed the efficiency of the proposed algorithm for a wide range of issues of various sizes.
\end{abstract}

Keywords: perishable supply chain; location-routing; multi-objective optimisation

\section{Introduction}

Manufacturers, suppliers, distributors, warehouses, retailers, and customers have expanded into global markets by establishing a network of organizations and operating a supply chain [1]. Regarding this issue, organizations always try to work together for common goals [2]. With the expansion and intensification of the competitive environment throughout the world, the optimal supply chain design has become one of the main issues facing businesses, and all the activities of the organizations to produce, improve quality, reduce costs, and provide services are affected [3]. On the other hand, with the increase in the volume of greenhouse gases and pollutants, managers and researchers attempt to design networks that, in addition to providing economic optimization, have also focused on environmental factors and reducing pollutants [3]. Currently, many countries pay increasing attention to environmental protection and enforcing ecological laws $[4,5]$. Hence, the industry owners and manufacturers have increasingly turned to supply chain design and development considering the environmental factors [6,7]. This study aims to design a mathematical programming model that identifies the best facility locations by considering procurement time, cost optimization, and customer satisfaction. In this supply chain, the manufacturer creates new goods and sends them to a consumer, and then the retailers 
purchase the goods and send them to the customers [8]. As the product is perishable, both quality and quantity may be reduced during the distribution process [9].

Furthermore, end users are sensitive to both the retail price and the innovation of the product [10]. Hence, market demand is stochastic and greatly depends on these two factors. Given the variable transport time and the level of product freshness, the decisions of the three parties involved in this supply chain are very complex and may lead to losses in cases of improper performance [11].

Considering the significance and role of location and routing problems in the multiechelon supply chain, this research attempts to design an optimal network that considers various objective functions in the perishable product supply chain (PPSC). According to this, four objective functions were considered, including minimizing each of the following: the costs, environmental pollution, shipping time for customer satisfaction, and the sales level. An efficient supply chain network must be designed to respond to uncertainties $[12,13]$.

This research investigated all the issues mentioned above using a synthesis approach: (1) Presenting multiple objective programming models for the four-echelon multi-product perishable supply chain network design problem. The model supports the selection of location, size, product flows, routes, and modes of transport across the supply chain. (2) Providing recommendations for the design and operation of a supply chain for yogurt as a perishable product in the case of the Sahra Gida in Turkey. The solution of the model is calculated based on data and regional characteristics such as type of yogurt, cost, mode of transport, and transport infrastructure. (3) Analysis of differentiation in the design of the perishable supply chain network design by modifying the weight of the objective functions in different scenarios, thereby assisting decision-makers in predicting changes in supply network configuration when the priority of the objective functions changes.

The structure of the paper is as follows: In the Section 2, the literature review will be examined. The Section 3 introduces the problem statement and the mathematical model, and the parameters, objective function, and constraints are stated. In Section 4, by proposing a heuristic algorithm, the designed problem is solved. The optimization method includes the hybrid approach of the Benders decomposition algorithm and the Lagrangian relaxation coefficient to solve the model. Finally, the conclusions and research implications for future studies are presented in Section 5.

\section{Review of Literature}

Perishable goods may not be stored for a long period of time and may decay during their transportation from one layer of the supply network to another. Furthermore, the ratio at which the goods deteriorate depends on the condition of the goods. For example, the goods may perish at a higher pace as the surrounding air temperature increases. On the other hand, the conditions under which the perishable goods are kept are affected by the design and planning of the chain. More specifically, the time during which the products remain in each facility and each vehicle is dependent on the supply network design. Therefore, the PPSC problem under uncertainty is an important aspect for the consideration of businesses working in the perishable industry.

Any supply chain aims to meet customer needs with the highest efficiency and lowest cost [14]. Indeed, the supply chain includes retailers, wholesalers, distributors, manufacturers, and suppliers, each meeting the needs of the customers or end-users [15]. Pishvaei et al. (2011) used a robust optimization under uncertainty to design a perishable product chain network. For this purpose, they developed a complex linear model and then, using the Benthal and Nemirovski method, scheduled a robust model, and then compared the model produced with the classic model using several examples [16]. De Keizer et al. (2017) have examined designing logistics networks for perishable products with a period of quality decline to optimize supply chain network design. The period of logistical operations and the environmental conditions during these operations significantly affect the performance of the logistics network for fresh agricultural products [8]. Rafieimajd et al. (2018) have presented a three-layer supply chain including suppliers, distribution centre, wholesaler, 
and retailer where the goods are delivered to customers within a finite time. Retailer demand is stochastic and follows a statistical distribution. In this research, the Lagrangian relaxation method was used for model solving [17]. Dai et al. (2018) have investigated the problem of designing a perishable products supply network with limited carbon emissions and full capacity. This study formulates a complex integer nonlinear programming model and uses the hybrid genetic algorithm (GA) and tabu search (TS) algorithm to minimize the total cost of the network [18]. Zhang and Yang (2020) consider designing a multi-objective mathematical model to calculate the exchange cost and environmental output in a two-tier green perishable supply network [19]. Rabbani et al. (2020) proposed a robust programming model for locating facilities in a multi-level, multi-period supply chain network by using a sustainable planning model to examine the various levels of vehicle routing, the value of returned products, and the amount of greenhouse gas emissions [20]. Based on the characteristics of the PPSC network design, the literature has been presented in Table 1.

Many studies have been conducted on the supply network design of perishable goods. A mathematical model is one of the most powerful tools for evaluating and allocating mathematical programming resources. In each of these studies, specific goals and limitations were examined, and one or two goals (mainly maximizing customer satisfaction and minimizing costs) were examined in most of them. Time plays a key role in the supply network of perishable products, and it will create a substantial financial loss and an environmental impact if there is a delay in the network process. To bridge this gap, this research tries to cover goals including minimizing costs and time of procurement and maximizing customer satisfaction by creating a combination of multiple manufacturers, suppliers, and distributors. For this study, the supplier is made up of few retailers and several markets, making it is feasible to gather, reuse, and demolish products. Therefore, this research develops a multi-objective optimized mathematical model for a yogurt supply chain network design problem, integrating the criteria mentioned above as factors and objectives. 
Table 1. A comparison of the mathematical models in PPSC network design.

\begin{tabular}{|c|c|c|c|c|c|c|c|c|c|c|c|c|}
\hline \multirow[b]{2}{*}{ Reference } & \multicolumn{3}{|c|}{ Model Type } & \multicolumn{3}{|c|}{ Structure } & \multirow[b]{2}{*}{ Location } & \multirow[b]{2}{*}{ Routing } & \multirow[b]{2}{*}{ Shortage } & \multicolumn{3}{|c|}{ Uncertainty } \\
\hline & LP & MILP & MINLP & $\begin{array}{c}\text { Multi- } \\
\text { Objective }\end{array}$ & $\begin{array}{c}\text { Multi- } \\
\text { Product }\end{array}$ & $\begin{array}{l}\text { Multi- } \\
\text { Period }\end{array}$ & & & & Fuzzy & Stochastic & Robust \\
\hline Baboli et al. (2011) [21] & $\checkmark$ & $x$ & $x$ & $x$ & $\checkmark$ & $x$ & $x$ & $x$ & $x$ & $x$ & $x$ & $x$ \\
\hline $\begin{array}{l}\text { Uthayakumar et al. } \\
\text { (2013) [23] }\end{array}$ & $\times$ & $x$ & $\checkmark$ & $x$ & $\checkmark$ & $x$ & $x$ & $x$ & $\checkmark$ & $\times$ & $\checkmark$ & $x$ \\
\hline $\begin{array}{l}\text { Mousazadeh et al. } \\
\text { (2015) [24] }\end{array}$ & $\times$ & $\checkmark$ & $x$ & $\checkmark$ & $\checkmark$ & $x$ & $\checkmark$ & $x$ & $x$ & $\checkmark$ & $x$ & $\times$ \\
\hline Zahiri et al. (2017) [25] & $\times$ & $\checkmark$ & $x$ & $\checkmark$ & $\checkmark$ & $\checkmark$ & $\checkmark$ & $x$ & $x$ & $\checkmark$ & $x$ & $x$ \\
\hline Zahiri et al. (2018) [26] & $\times$ & $\checkmark$ & $\times$ & $\checkmark$ & $\checkmark$ & $\checkmark$ & $\checkmark$ & $x$ & $x$ & $x$ & $x$ & $\checkmark$ \\
\hline $\begin{array}{l}\text { Sabouhi et al. } \\
\text { (2018) [27] }\end{array}$ & $\times$ & $\checkmark$ & $x$ & $x$ & $\checkmark$ & $x$ & $\checkmark$ & $x$ & $x$ & $x$ & $\checkmark$ & $\times$ \\
\hline $\begin{array}{l}\text { Singh and Goh } \\
\text { (2019) [28] }\end{array}$ & $\times$ & $\checkmark$ & $x$ & $\checkmark$ & $\checkmark$ & $\checkmark$ & $x$ & $\checkmark$ & $x$ & $\checkmark$ & $x$ & $\times$ \\
\hline $\begin{array}{l}\text { Savadkoohi et al. } \\
\text { (2019) [29] }\end{array}$ & $x$ & $x$ & $\checkmark$ & $\times$ & $\checkmark$ & $\checkmark$ & $\checkmark$ & $x$ & $\checkmark$ & $\checkmark$ & $\times$ & $x$ \\
\hline $\begin{array}{c}\text { Nasrollahi and Razmi } \\
(2019)[30]\end{array}$ & $\times$ & $\checkmark$ & & $\checkmark$ & $\checkmark$ & $\checkmark$ & $\checkmark$ & $\checkmark$ & $\checkmark$ & $x$ & $x$ & $\checkmark$ \\
\hline $\begin{array}{l}\text { Akbarpour et al. } \\
\quad(2020)[31]\end{array}$ & $x$ & $x$ & $\checkmark$ & $\checkmark$ & $\checkmark$ & $\checkmark$ & $\checkmark$ & $x$ & $\checkmark$ & $x$ & $\checkmark$ & $\times$ \\
\hline This Research & $x$ & $\checkmark$ & $x$ & $\checkmark$ & $\checkmark$ & $\checkmark$ & $\checkmark$ & $\checkmark$ & $\checkmark$ & $x$ & $\checkmark$ & $x$ \\
\hline
\end{tabular}




\section{Model Formulation}

In recent years, many researchers have focused on the field of supply chains $[9,18,32]$. The purpose of anyone active in the supply chain is to increase competitiveness or increase customer service [33]. The supply chain considers all the organizations involved [32-34]. This shows the effect of cost and time on customer satisfaction. Overall, the study objectives are as follows:

- determining the location of manufacturers, retailers, and distributors;

- establishing coordination between network levels to minimize cost and procurement time;

- creating a balance between reducing the costs and procurement time, and maximizing customer satisfaction.

We assume a supply chain with four echelons-specific suppliers (I), multiple manufacturers $(\mathrm{J})$, multiple distributors $(\mathrm{K})$, and customers $(\mathrm{L})$ - and we intend to locate them correctly to minimize the cost and procurement time and maximize customer satisfaction. Accordingly, the manufacturer procures the needed raw materials from three suppliers who have suitable conditions based on his needs. The manufacturer then delivers the final product during the manufacturing process. The final goods must be delivered to distributors in a short time. The multi-objective optimization method has been solved using GAMS 24 software (CPLEX solver), and the hybrid method of the Benders decomposition algorithm and Lagrangian relaxation is used to solve this model.

The supply chain network has four echelons: suppliers, manufacturers, distributors, and retailers. The study optimized a suitable location to optimize the time, cost of procurement and obtain customer satisfaction. Accordingly, the manufacturer procures the raw materials needs from suppliers. The manufacturer then transfers its product to the distributor(s) in a short time. Distributors must deliver to a few retailers after the product is delivered, at which point the product may be damaged.

The four objectives are minimizing cost, greenhouse gas emissions, and preparation time, and maximizing customer satisfaction. There have been different divisions of the study on reducing costs, and in some studies, this goal has even been replaced by maximizing profits by focusing on the difference between income and expenses. The cost variables include the costs of establishing a place for production [35] and a place for distribution [36], determining a location for retail [35], transportation costs [37], raw material costs [9], ordering costs [10], production costs [38], delayed payment penalties [38], cost of lost orders [39], inventory maintenance cost [37], cost of returned perishable goods [38], shipping costs for returned goods, and environmental costs.

The next goal takes into account the preparation time related to the quality of the goods, considering the sensitivity of perishable goods [40]. Procurement time depends on different factors, regardless of the perishability of long-lasting goods. Different paths exist between points (supplier and manufacturer/manufacturer and distributor/distributor and customer) where the shortest route has to be selected to reduce supply time and shipping costs. The type of vehicle considered for transportation is also essential, as each device has a specific capacity to complete the delivery with a certain amount of load. The type of shipping route, such as whether it is smooth or mountainous, will affect the time of shipment as well.

\subsection{Mathematical Model}

\subsubsection{Assumptions}

In this section, the assumptions related to the designed model are explained.

- A time window is determined for each customer.

- A similar vehicle is not used for transportation.

- The time duration is one week.

- Manufacturers and distribution centers have limited capacity.

- Suppliers and retailers are allowed to store goods and can order more than needed. 
- Various products are considered.

- Retailers and distribution centers cannot return their orders.

- Each section has a particular travel cost and distance.

- All demands of the customer must be met on the assumption that they can buy from multiple distributors.

- Fixed cost of the equipment should be considered for internal transportation costs.

The indices, parameters, and variables of the proposed model are as follows:

3.1.2. Indices

I: The set of suppliers $i \in\{1,2, \ldots, I\}$

$\mathrm{J}$ : The set of production centers $j \in\{1,2, \ldots, J\}$

$\mathrm{K}$ : The set of distribution centers $k \in\{1,2, \ldots, K\}$

L: The set of customers $l \in\{1,2, \ldots, L\}$

P: The set of products $l \in\{1,2, \ldots, L\}$

$\tau$ : The set of raw materials $\tau \in\{1,2, \ldots, \tau\}$

M: The set of means of transportation (facilities) $m \in\{1,2, \ldots, M\}$

T: Time period $t \in\{1,2, \ldots, T\}$

G: Product group $g \in\{1,2, \ldots, G\}$

A: Supplier capacity level $a \in\{1,2, \ldots, A\}$

B: Producer capacity level $b \in\{1,2, \ldots, B\}$

C: Distributor capacity level $c \in\{1,2, \ldots, C\}$

\subsubsection{Parameters}

$\widetilde{\theta}_{l t}^{p}$ : Customer $l$ demand for the product $\mathrm{p}$ in time $t$ time $\mathrm{t}$

$\omega_{\tau p t}$ : Consumption rate of raw materials $\tau$ in the production of the product $\mathrm{p}$ in a

$\phi_{p g t}: \mathrm{g}$ group of product $\mathrm{p}$ in time $\mathrm{t}$

$\widetilde{S}_{i \tau}^{a t}$ : Maximum capacity of supplier i with specific raw materials $\tau$ in time $t$

$\widetilde{M}_{j p}^{b t}$ : Maximum production capacity of manufacturer $\mathrm{j}$ with the capacity $\mathrm{b}$ for the product $p$ in time $t$.

$\widetilde{D}_{k g}^{c t}$ : Maximum distribution capacity of retailer $\mathrm{k}$ with capacity $\mathrm{c}$ for product group $\mathrm{g}$ in time $\mathrm{t}$

$A_{i t}$ : Minimum number of selected suppliers $i$ in the time $\mathrm{t}$

$\widehat{B}_{j t}$ : Minimum number of selected producers $\mathrm{j}$ in the time $\mathrm{t}$

$\widehat{C}_{k t}$ : Minimum number of selected distributors $\mathrm{k}$ in the time $\mathrm{t}$

$\widetilde{F}_{i j}$ : Spatial distance between supplier i to manufacturer $j$

$\widetilde{W}_{j k}:$ Spatial distance between manufacturer $\mathrm{j}$ and retailer $\mathrm{k}$

$\widetilde{H}_{k l}$ : Spatial distance between retailer $\mathrm{k}$ and customer 1

$\sigma_{\tau}$ : Raw materials $\tau$ unit

$V_{p}$ : Product unit $\mathrm{p}$

$E_{i t}^{a}$ : Fixed and operating costs of selecting the supplier $i$ with capacity $a$ at period $t$

$Q_{j t}^{b}$ : Fixed and operating cost of constructing a manufacturer $j$ with capacity $b$ in period $t$

$N_{k t}^{c}$ : Fixed and operating cost of constructing of distributor with capacity $c$ over period $t$

$R_{m}$ : The cost of each unit of transportation of raw materials based on the distance between the levels according to the type of means of transportation $m$

$U_{m}$ : The cost of each unit of product transportation based on the distance between the levels according to the type of means of transportation $m$

$\in_{i t}^{a}$ : The cost of GGE of selected supplier $i$ with a capacity $a$ over time $t$

$\eta_{j t}^{b}$ : The cost of GGE from the manufacturer $j$ with capacity $b$ over time $t$

$v_{k t}^{c}$ : The cost of GGE by retailer $k$ with a capacity $c$ over time $t$ 
$\widetilde{\lambda}_{m}$ : Greenhouse gas emission coefficient of each raw material transport unit based on the distance according to the type of means of transportation vehicle $m$

$\widetilde{\mu}_{m}$ : Emission coefficient of greenhouse gases of each product transportation unit based on the distance between the surfaces according to the type of transportation vehicle $\mathrm{m}$

\subsubsection{Variables}

$\alpha_{i t}^{a}=\left\{\begin{array}{l}1 \\ 0\end{array}\right.$ Binary variable, if the supplier $i$ with the capacity a in the time $t$ is selected 1 otherwise equal to zero.

$\beta_{j t}^{b}=\left\{\begin{array}{l}1 \\ 0\end{array}\right.$ Binary variable, if the manufacturer $\mathrm{j}$ with the capacity $\mathrm{b}$ is produced in the time $t$ is 1 otherwise equal to zero.

$\gamma_{k t}^{c}=\left\{\begin{array}{l}1 \\ 0\end{array}\right.$ Binary variable, if the retailer $\mathrm{k}$ with the capacity $\mathrm{c}$ is constructed in the period $t$ is 1 otherwise equal to zero.

$\widetilde{X}_{i j}^{\tau t m}$ : The amount of raw materials $\tau$ moved from the supplier $i$ to the manufacturer $j$ in the period $t$ according to the type of transportation vehicle $m$

$\widetilde{Y}_{j k}^{p t m}$ : The value of the product $\mathrm{p}$ moved from the producer $\mathrm{j}$ to the retailer $\mathrm{k}$ in the period $\mathrm{t}$ according to the type of transportation vehicle $\mathrm{m}$

$\widetilde{Z}_{k l}^{p t m}$ : The value of product $\mathrm{p}$ moved from the retailer $\mathrm{k}$ to the customer 1 in the period $t$ according to the type of transportation vehicle $m$.

\subsubsection{Objective Functions}

$$
\begin{aligned}
\text { Min } F_{E c o} & =\sum_{i} \sum_{a} \sum_{t} E_{i t}^{a} \cdot \alpha_{i t}^{a}+\sum_{j} \sum_{b} \sum_{t} Q_{j t}^{b} \cdot \beta_{j t}^{b}+\sum_{k} \sum_{c} \sum_{t} N_{k t}^{c} \cdot \gamma_{k t}^{c} \\
& +\sum_{i} \sum_{j} \sum_{\tau} \sum_{t} \sum_{m} \widetilde{F}_{i j t} \cdot R_{m} \cdot \sigma_{\tau} \widetilde{X}_{i j}^{\tau t m}+\sum_{j} \sum_{k} \sum_{p} \sum_{t} \sum_{m} G_{j k t} \cdot U_{m} \cdot V_{p} \cdot \widetilde{Y}_{j k}^{p t m} \\
& +\sum_{k} \sum_{l} \sum_{p} \sum_{t} \sum_{m} \widetilde{H}_{k l} \cdot U_{m} \cdot V_{p} \cdot \widetilde{Z}_{k l}^{p t m} \\
\text { Min } \quad F_{E n v}= & \sum_{i} \sum_{a} \sum_{t} \in_{i t}^{a} \alpha_{i t}^{a}+\sum_{j} \sum_{b} \sum_{t} \eta_{j t}^{b} \cdot \beta_{j t}^{b}+\sum_{k} \sum_{c} \sum_{t} v_{k t}^{c} \cdot \gamma_{k t}^{c} \\
& +\sum_{i} \sum_{j} \sum_{\tau} \sum_{t} \sum_{m} \widetilde{F}_{i j t} \lambda_{m} \cdot \sigma_{\tau} \widetilde{X}_{i j}^{\tau t m}+\sum_{j} \sum_{k} \sum_{p} \sum_{t} \sum_{m} G_{j k t} \cdot \mu_{m} \cdot V_{p} \cdot \widetilde{Y}_{j k}^{p t m} \\
& +\sum_{k} \sum_{l} \sum_{p} \sum_{t} \sum_{m} \widetilde{H}_{k l} \cdot \mu_{m} \cdot V_{p} \cdot \widetilde{Z}_{k l}^{p t m} \\
\text { Min } \quad & F_{\text {delivery-time }}=\sum_{i} \sum_{m} \sum_{j} \sum_{k} \sum_{t}\left(\frac{\widetilde{\theta}_{l t}^{p}}{R_{m}+U_{m}}\right) \widetilde{Y}_{j k}^{p t m} \\
& \text { Min } \quad F_{\text {Backorder-level }}=\sum_{t} \operatorname{Max} \sum_{p} \sum_{k} \widetilde{Z}_{k l}^{p t m}
\end{aligned}
$$

The first objective function (OF) is responsible for reducing the network costs: first, the fixed and operating costs of the supplier selection process; second, the handling cost of the manufacturer; third, the fixed and operating costs of the distributor; fourth, cost of transportation of raw materials by distance; fifth, the cost of transferring the product from the producer to the retailers; and sixth, the cost of moving each unit of product from the retailer to the consumer. The second $\mathrm{OF}$ is to minimize environmental criteria: first, the cost of greenhouse gas emissions (GGE) from supplier; second, the cost of GGE from the manufacturer; third, the cost of GGE from the distributor; fourth, the cost of GGE generated because of the transportation of raw materials from the supplier to the producer; fifth, the cost of GGE from the transportation of the product from the manufacturer to the retailers; sixth, the cost of GGE from shipping the product from the distributor to the consumers. The third and fourth OFs of customer satisfaction are eliminated by minimizing shipping time 
and sales level. The receiving time of perishable goods, perishability rate of the product, transportation time of goods between each section of the supply chain, and the capacity of supply chain entities are the main characteristics of the designed model.

3.1.6. Constraints

$$
\begin{gathered}
\sum_{j} \widetilde{X}_{i j}^{\tau t} \leq \sum_{a} \widetilde{S}_{i \tau}^{a t} \cdot \alpha_{i t}^{a} \quad \forall i, \tau, t \\
\sum_{k} \widetilde{Y}_{j k}^{p t} \leq \sum_{b} \widetilde{M}_{j p}^{b t} \cdot \beta_{j t}^{b} \quad \forall j, p, t \\
\sum_{l} \sum_{p} V_{p} \widetilde{Z}_{k l}^{p t} \cdot \phi_{p g t} \leq \sum_{c} \widetilde{D}_{k g}^{c t} \cdot \gamma_{k t}^{c} \quad \forall k, g, t \\
\sum_{j} X_{i j}^{\tau} \geq \sum_{k} \sum_{p} \widetilde{Y}_{j k}^{p} \omega_{\tau p t} \quad \forall j, \tau, t \\
\sum_{j} \widetilde{Y}_{j k}^{p t} \geq \sum_{l} \widetilde{Z}_{k l}^{p t} \cdot \alpha_{i t}^{a} \quad \forall k, p, t \\
\sum_{k} \widetilde{Z}_{k l}^{p t} \geq \widetilde{\theta}_{l t}^{p} \quad \forall l, p, t \\
\sum_{a} \alpha_{i t}^{a} \leq 1 \quad \forall i, t \\
\sum_{b} \beta_{j t}^{b} \leq 1 \quad \forall j, t \\
\sum_{c} \gamma_{k t}^{c} \leq 1 \quad \forall k, t \\
\sum_{i} \sum_{a} \sum_{t} \alpha_{i t}^{a} \leq \hat{A}_{i t} \\
\sum_{j} \sum_{b} \sum_{t} \beta_{j t}^{b} \leq \hat{B}_{j t} \\
\sum_{k} \sum_{c} \sum_{t} \gamma_{k t}^{c} \leq \hat{C}_{k t} \\
\widetilde{X}_{i j}^{\tau t}, \widetilde{Y}_{j k}^{p t}, \widetilde{Z}_{k l}^{p t} \geq 0 \\
\alpha_{i t}^{a}, \beta_{j t}^{b}, \gamma_{k t}^{c} \in\{0,1\}
\end{gathered}
$$

Constraint (5) shows that the value of raw material transferred from the supplier to the producer does not exceed the maximum capacity of the specific supplier. Constraint (6) shows that the weight of the product moved from the producer to the retailer should not exceed the maximum production capacity of the producer. Constraint (7) shows that the maximum distribution capacity of the distributor $\mathrm{k}$ with the capacity $\mathrm{c}$ for the product group $g$ in the period $t$ should not be more than the defined capacity level. Constraint (8) shows that the value of raw material transferred from the supplier to the producer must be equal to the value of raw material needed to make the entire product so that we do not face a shortage of raw materials. According to constraint (9), the product's value moved from the manufacturer to the retailer must be equal to the value of goods moved from the distributor to the customer so that we do not suffer from shortages. Constraint (10) show that the value of the goods from the retailer to the consumer is equal to the market demand. Constraint (11) shows that a maximum of each selected supplier at any one time. 
Constraint (12) presents the number of producers at a maximum of one at any one time. Constraint (13) considers the number of retailers at any one time to be a maximum of 1 . Constraints (14) to (16) show that the minimum required number of selected suppliers must equal the number of suppliers. Constraints (17) and (18) are logical constraints.

\section{Solution Approach}

In order to solve the designed model, a hybrid approach was developed based on the combination of Benders decomposition (BD) [41,42] and Lagrangian Relaxation (LR) algorithms. The $\mathrm{BD}$ is limited to convex optimization problems and the LR can overcome this limitation. In this way, the bounds of BD are developed and the calculation time is decreased while $\mathrm{BD}$ allows the problem to converge at finite iterations. The $\mathrm{BD}$ divides the original model into a main problem and a sub-problem, and the LR creates acceptable approximate solutions for the main problem by relaxing all constraints and providing some information on the optimal solution of the main problem. Such a combined BD-LR approach represents an efficient method to solve the mathematical model and achieve a satisfactory optimal solution. In this section, the proposed combined BD-LR solution approach is described.

Using this composition, stronger bounds with higher effectiveness and lower iterations are captured in order to gain optimal solution. Specifically, obtained lower bound by LR is always better than obtained lower bound by $\mathrm{BD}$, so convergence is guaranteed by the hybrid method. The Benders cut is optimality used along with the NBD. Herein, we have forward and backward passes. The aim of the forward pass region is to solve the original problem (M) to obtain a lower bound on $M\left(x_{1}\right)$. In the backward pass, the aim is to generate valid Bender's optimality cuts using trial $x_{t+1}$. By $\hat{L}_{1}\left(x_{1}\right)-M\left(x_{1}\right) \geq 0$, there is a gap between the lower bound $Z$ and the upper bound $z-$, which do not converge. Using the combined $\mathrm{BD}$ and LR, the solution to $M$ and $M\left(x_{1}\right)$ is found. We can obtain the bounds by computing the optimality cuts on a relaxed problem. If the problem has a gap, as represented by $\hat{L}_{1}\left(x_{1}\right)-M\left(x_{1}\right) \geq 0, M$ and the combined BD and LR cannot solve $L$. For stage $t$, the computed cut is tight for $L_{T}\left(M_{T}\right)$, but after multiple backward and forward passes, the computed cuts in $h_{t}\left(x_{t}\right)-g_{l_{t}}\left(x_{t+1}, y_{t}\right) \leq 0$ will be tight for all other stages. The steps of the proposed Algorithm 1 are as follows:

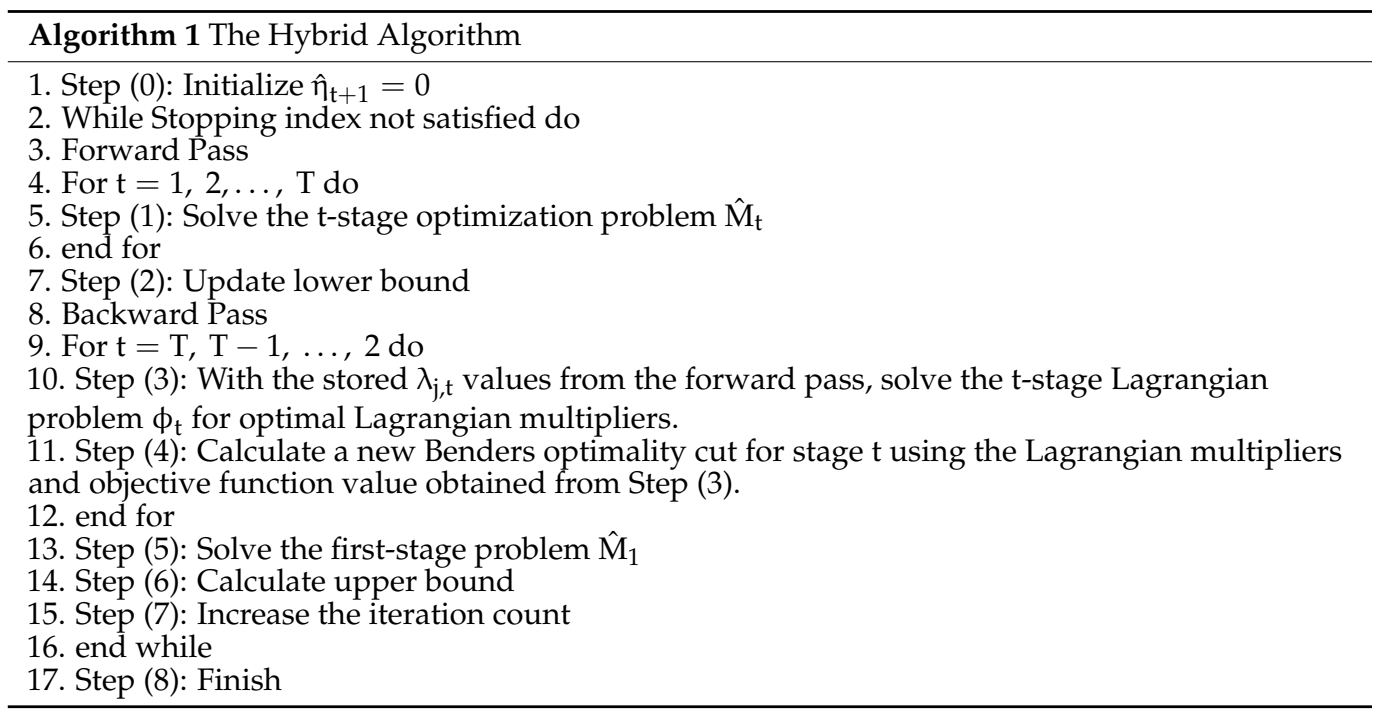

The $\mathrm{BD}$ method is related to the analysis of a mixed integer linear programming with a problem and a subproblem that are solved repeatedly using each other's answers. The subproblem consists of continuous variables and their constraints, while the main problem consists of the integer variables and a continuous variable that connects the two problems. 
Before developing the main problem and sub-problem, the formulation of the problem can be expressed as follows:

$$
\operatorname{Min} F=\sum_{i} \sum_{a} \sum_{t} E_{i t}^{a} \cdot \alpha_{i t}^{a}+\sum_{j} \sum_{b} \sum_{t} Q_{j t}^{b} \cdot \beta_{j t}^{b}+\sum_{k} \sum_{c} \sum_{t} N_{k t}^{c} \cdot \gamma_{k t}^{c}+B S P(x, y \mid \hat{U}, \hat{V})
$$

s.t

$$
\text { Equations (10) - (13) }
$$

$\operatorname{BSP}(x, y \mid \hat{U}, \hat{V})$ is the Benders subproblem and is explained as follows:

\subsection{Benders Sub-Problem}

The $\operatorname{BSP}(x, y \mid \hat{U}, \hat{V})$ sub-problem is a minimization problem that obtains the optimal value of $(x, y)$ continuous variables for $(\hat{U}, \hat{V})$ fixed variables. This can be shown as follows:

$$
\begin{gathered}
\operatorname{Min} F=\sum_{i} \sum_{j} \sum_{\tau} \sum_{t} \sum_{m} \widetilde{F_{i j j}} \cdot R_{m} \cdot \widetilde{\sigma_{\tau}} \widetilde{X_{i j}^{\tau t m}}+\sum_{j} \sum_{k} \sum_{p} \sum_{t} \sum_{m} G_{j k t} \cdot U_{m} \cdot V_{p} \cdot \widetilde{Y_{j k}^{p t m}} \\
+\sum_{k} \sum_{l} \sum_{p} \sum_{t} \sum_{m} \widetilde{H_{k l}} \cdot U_{m} \cdot V_{p} \cdot \widetilde{Z_{k l}^{p t m}}
\end{gathered}
$$

s.t.

$$
\text { Equations (2) - (10), (14) - (18) }
$$

Dual $\operatorname{BSP}(x, y \mid \hat{U}, \hat{V})$ is used to produce Benders cuts for the main problem. To obtain the duality of this problem, dual variables $\pi_{i j m}^{1}, \pi_{i j m}^{2}, \pi_{j m}^{3}, \pi_{j p m}^{4}, \pi_{k m}^{5}, \pi_{p t m}^{6}, \pi_{l p t}^{7}, \pi_{k m}^{8}$ are used for each constraint. Considering these variables, the dual problem under the problem named $\operatorname{BSP}\left(\pi^{1}, \pi^{2}, \pi^{3}, \pi^{4}, \pi^{5}, \pi^{6}, \pi^{7}, \pi^{8} \mid \hat{U}, \hat{V}\right)$ will be as follows:

$$
\max \sum_{i} \sum_{j} \sum_{m}\left(-\pi_{i p m}^{1}+\pi_{i p m}^{2}\right)-\sum_{j} \sum_{m}\left(\pi_{j m}^{3} \cdot V_{p} \cdot \widetilde{Y_{j k}^{p t m}}\right)-\sum_{k} \sum_{m}\left(\pi_{k m}^{5} \cdot V_{p} \cdot \widetilde{Z_{k l}^{p t m}}\right)
$$

s.t.

$$
\begin{gathered}
-\pi_{i p m}^{1}+\pi_{i p m}^{2}-\widetilde{F_{i j t}} \cdot R_{m} \cdot \sigma_{\tau} \pi_{j m}^{3} \leq \widetilde{S_{i t}^{a t}} \alpha_{i t}^{a} \\
\phi_{j p t} \pi_{j p m}^{4}-\omega_{p t} \pi_{k m}^{5} \leq \widetilde{Z_{k l}^{p t}} \alpha_{i t}^{a} \\
\pi_{p t m}^{6}+\pi_{l p t}^{7}-\pi_{k m}^{8} \beta_{j t}^{b} \leq \hat{B_{j t}} \\
\pi_{i j m}^{1}, \pi_{i j m}^{2}, \pi_{j m}^{3}, \pi_{j p m}^{4}, \pi_{k m}^{5}, \pi_{p t m}^{6}, \pi_{l p t}^{7}, \pi_{k m}^{8} \geq 0
\end{gathered}
$$

\subsection{Benders Main-Problem}

The main problem of Benders is modeled as follows:

$$
\min _{U, V} z
$$

s.t.

$$
\begin{gathered}
z \geq \sum_{i} \sum_{a} \sum_{t} E_{i t}^{a} \cdot \alpha_{i t}^{a}+\sum_{j} \sum_{b} \sum_{t} Q_{j t}^{b} \cdot \beta_{j t}^{b}+\sum_{k} \sum_{c} \sum_{t} N_{k t}^{c} \cdot \gamma_{k t}^{c}+\sum_{i} \sum_{j} \sum_{m}\left(-\pi_{i p m}^{1 k}\right. \\
\left.+\pi_{i p m}^{2 k}\right)-\sum_{j} \sum_{m}\left(\pi_{j m}^{3 k} \cdot V_{p} \cdot \widetilde{Y_{j k}^{p t m}}\right)-\sum_{k} \sum_{m}\left(\pi_{k m}^{5 k} \cdot V_{p} \cdot Z_{k l}^{p t m}\right) \\
\sum_{i} \sum_{j} \sum_{m}\left(-\pi_{i p m}^{1 l}+\pi_{i p m}^{2 l}\right)-\sum_{j} \sum_{m}\left(\pi_{j m}^{3 l} \cdot V_{p} \cdot \widetilde{Y_{j k}^{p t m}}\right)-\sum_{k} \sum_{m}\left(\pi_{k m}^{5 l} \cdot V_{p} \cdot \widetilde{Z_{k l}^{p t m}}\right) \leq 0 \\
\text { Equations }(10)-(13)
\end{gathered}
$$


In this model, Equation (28) represents the objective function of the main problem of BD. Equation (29) is optimization cuts that are added to the main problem after reaching the optimal solution of the sub-problem.

As is clear from the following pseudo-code, we must first find a solution to the main problem; this is done by solving the main problem without any cuts; then, the answers obtained for the main problem are given for the sub-problem. The BD problem is solved; if the sub-problem is not possible and the dual answer is under the feasible problem, a feasible cut is taken from the dual. It can be problematic and has an optimal answer. Using the optimal solutions under the sub-problem, a generated optimization cut is added to the main problem. If the obtained answer provides a better upper limit, the upper limit is updated. The main problem is then updated using the new re-solved lower cut. This is repeated five times until the distance between the upper and lower limits is less than a certain value (Figure 1).

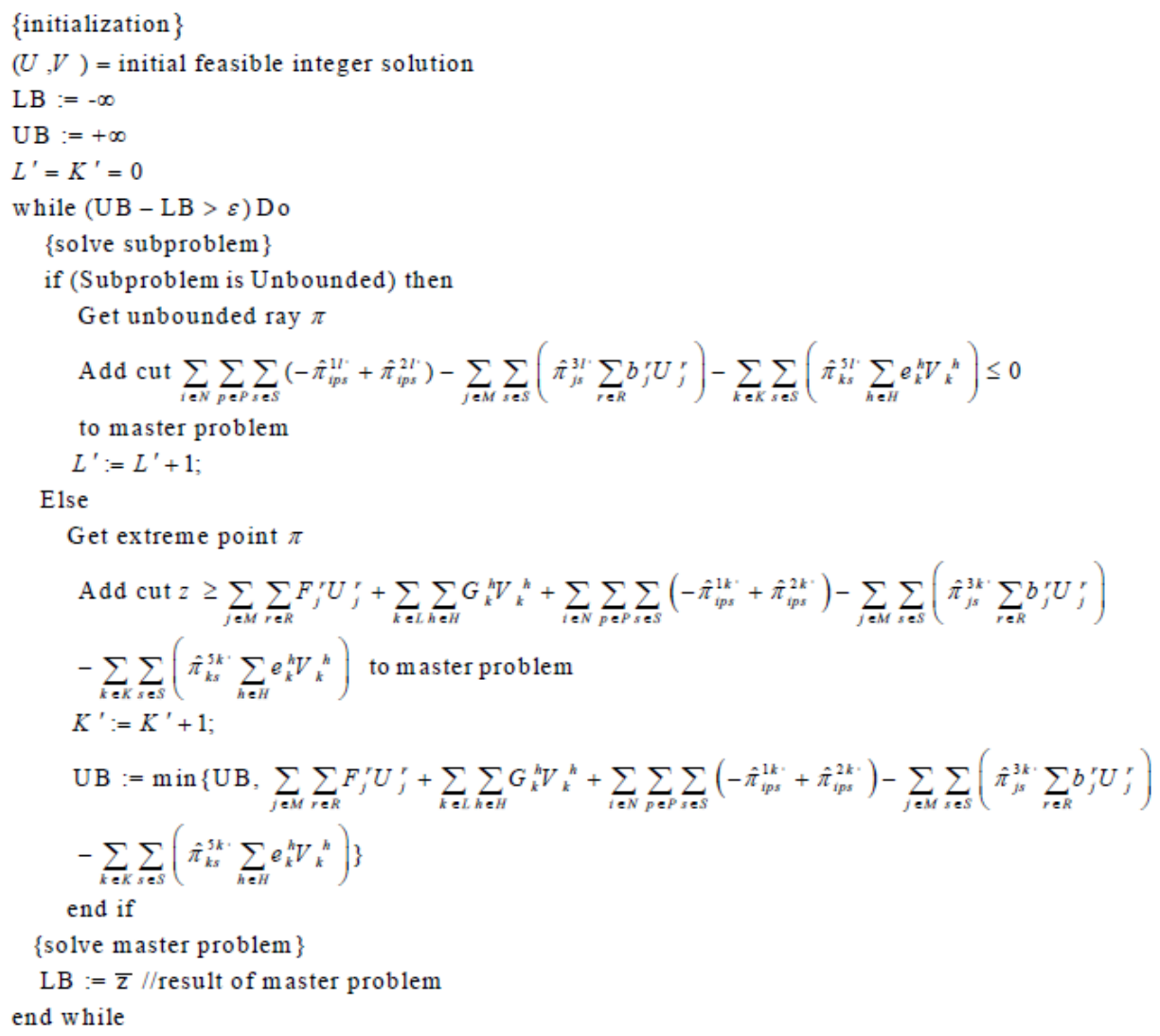

Figure 1. Algorithm of calculation.

\section{Results}

The binary variables for organizing the supply chain are first identified, and then the continuous variables showing the volume of products and displacements are stated. For the initial optimization, the hybrid method of Bender analysis and the Lagrangian relaxation coefficient was used. The model's information is updated. SCIP, stated in the solution method, is software that performs mixed linear programming optimization and is based on the combined process of Benders analysis and the Lagrangian coefficient. In the constraint method, one of the known approaches to solving problems, the multi-objective mathematical model, is used by moving OFs (except for one of them) to constraint.

GAMS (CPLEX solver) and MATLAB 17 software, along with the hybrid method of Benders analysis and the Lagrangian coefficient, were used and based on the studied data tables, results are obtained. The relative weight of the stability of the answer $(\mathfrak{\omega})$ is 0.5 , 
and the relative weight of the model stability $(\omega)$ is considered 6000. Demand data were extracted based on sales data from the last three years of the case study.

Tables 1 and 2 present an overview of the supply chain planning outcome, outlining supplier selection and demand response methods. The terms "supplier to site," or "site to customer's zone" show the answer appropriately. The first phrase means the supply of raw materials needed by site $j$ from supplier $i$, and the second phase is the amount of response to customer needs through site $j$. The empty cells in Table 1 are equal to zero, meaning that the product was not delivered to the customer during the ordering period. Moreover, the first column shows the type of product, the second column shows the active sites for each product, and the third column shows the kind of production in different periods. These types of considerations in the transportation system can be extracted as shown in Table 2.

Table 2. The results of designed supply chain planning.

\begin{tabular}{|c|c|c|c|c|c|c|c|c|c|c|c|c|c|}
\hline \multirow{2}{*}{ Product } & \multirow{2}{*}{ Factory } & \multicolumn{12}{|c|}{ Period } \\
\hline & & 1 & 2 & 3 & 4 & 5 & 6 & 7 & 8 & 9 & 10 & 11 & 12 \\
\hline \multirow[t]{3}{*}{1} & 1 & 19.3 & 352 & 304 & & & & & & & & & \\
\hline & 2 & 202 & 823 & 755 & 659 & 331 & 437 & 212 & & & & & \\
\hline & 3 & 238 & & 499 & 586 & 124 & 327 & 266 & & & & & \\
\hline \multirow[t]{3}{*}{2} & 1 & 915 & 1132 & 650 & 991 & & 228 & 194 & 53 & & 92 & & \\
\hline & 2 & 454 & 191 & 213 & 562 & 687 & 544 & 862 & 928 & & & & \\
\hline & 3 & & & & 42 & 574 & 301 & & 931 & 672 & 563 & & \\
\hline \multirow[t]{3}{*}{3} & 1 & 275 & 225 & 241 & & & 122 & 107 & 109 & 534 & 321 & 403 & \\
\hline & 2 & 200 & 970 & 768 & 830 & 160 & 90 & & 300 & 620 & 593 & 550 & \\
\hline & 3 & 39.6 & & 102 & 780 & 250 & & & & & & & \\
\hline \multirow[t]{3}{*}{4} & 1 & 482 & 283 & 729 & 407 & & 130 & 237 & 353 & & & & \\
\hline & 2 & 767 & 516 & 655 & 626 & 930 & 280 & 427 & 387 & 833 & & & \\
\hline & 3 & & & & 226 & 200 & & & 107 & & & & \\
\hline \multirow[t]{5}{*}{5} & 1 & 742 & 1090 & 717 & 1047 & 991 & 753 & 483 & 183 & 353 & 370 & & \\
\hline & & & & 230 & & 170 & & & 277 & & & & \\
\hline & 2 & 399 & 5.8 & & 73.4 & 367 & 164 & 320 & 66.5 & & & & \\
\hline & & & & & & 280 & 170 & & & & & & \\
\hline & 3 & 70 & 170 & 150 & 333 & 598 & 277 & & 20 & 349 & & & \\
\hline
\end{tabular}

Table 3 deals with the transportations realized through the chain transport system. Based on what we expected, the factory-customer demand was met by close sources. However, there are some shortages where even with the savings in other costs, the cost of disconnected communication between demand points and suppliers has not been offset. Additionally, in the downstream, two factors have not been well addressed, namely in relation to site $2 \rightarrow$ customer's zone 1 and site $2 \rightarrow$ customer's zone 3 . There are two reasons for this: the settings created because of the constraints of the chain, and the changes in the re-filling of raw materials in Factory 2 may occur in various repetitions. Table 4 shows the interactions between the supply chain entities against different values of the $\omega$ coefficient. For instance, when $\omega=1500,12$ construction sites have been upgraded from level 2 to level 3 in period 1, and site 3 , and 2 construction sites in factory 1 and period 2, are upgraded from level 3 to level 5 .

The general stable multi-objective programming model is presented; it is a fourobjective complex integer problem whose objective functions conflict with each other. Multi-criteria capture is used to solve models with conflicting OFs. Based on the procedure stated in the literature review section, by considering each objective function separately and solving the problem of two or more objectives, we obtain the optimal answer to each objective function individually. Two models have been expressed to further analyse these objectives because of the simultaneous importance of four general loss goals in the production system and the supply chain and customer satisfaction. 
Table 3. Transportation planning results.

\begin{tabular}{|c|c|c|c|c|c|c|c|c|c|c|c|c|c|c|}
\hline \multirow{2}{*}{ Section } & \multirow{2}{*}{ Product } & \multirow{2}{*}{ Factory } & \multicolumn{12}{|c|}{ Period $(t)$} \\
\hline & & & 1 & 2 & 3 & 4 & 5 & 6 & 7 & 8 & 9 & 10 & 11 & 12 \\
\hline \multirow[t]{10}{*}{ Transport } & 1 & 1 & 6 & 2 & 1 & & & & & & & & & \\
\hline & & 2 & 5 & 5 & 5 & 2 & & & & & & & & \\
\hline & & 3 & 8 & 8 & 8 & 3 & & & & & & & & \\
\hline & 2 & 1 & 6 & 4 & 1 & 1 & 1 & 1 & 1 & & & & & \\
\hline & & 2 & 10 & 10 & 4 & 2 & 2 & 2 & & & & & & \\
\hline & & 3 & 22 & 17 & 10 & 10 & 10 & 10 & 10 & 7 & 7 & 5 & 4 & 4 \\
\hline & 3 & 2 & 15 & 8 & 8 & 88 & 8 & 8 & 8 & 8 & 8 & 8 & 8 & 8 \\
\hline & & 3 & 5 & & & & & & & & & & & \\
\hline & 4 & 1 & 3 & 2 & & & & & & & & & & \\
\hline & 5 & 1 & 6 & 7 & 9 & 9 & 6 & 4 & 4 & 4 & 3 & 3 & 3 & 3 \\
\hline \multirow[t]{14}{*}{ Customer } & 1 & 1 & & 4 & 1 & 1 & & & & & & & & \\
\hline & & 2 & & & & 3 & 2 & & & & & & & \\
\hline & & 3 & & & & 5 & 3 & & & & & & & \\
\hline & 2 & 1 & & 2 & 3 & & & & & 1 & & & & \\
\hline & & 2 & & & 6 & 2 & & & 2 & & & & & \\
\hline & & 3 & & 5 & 7 & & & & & 3 & & 2 & 1 & \\
\hline & 3 & 1 & 6 & & & & & & & & & & & \\
\hline & & 2 & & 7 & & & & & & & & & & \\
\hline & & 3 & 15 & 5 & & & & & & & & & & \\
\hline & 4 & 1 & 6 & & 3 & & & & & & & & & \\
\hline & & 2 & 3 & 2 & & & & & & & & & & \\
\hline & 5 & 1 & & & & & 3 & 2 & & & 1 & & & \\
\hline & & 2 & 10 & & & & & & & & & & & \\
\hline & 5 & 1 & & 1 & 2 & & & & & & & & & \\
\hline
\end{tabular}

Table 4. Enhancing the efficiency level against the model stability coefficient.

\begin{tabular}{|c|c|c|c|c|c|c|c|c|c|c|c|c|c|c|}
\hline \multirow{2}{*}{$\omega$} & \multirow{2}{*}{ Echelon Upgrade } & \multirow{2}{*}{ Factory } & \multicolumn{12}{|c|}{ Period $t$} \\
\hline & & & 1 & 2 & 3 & 4 & 5 & 6 & 7 & 8 & 9 & 10 & 11 & 12 \\
\hline \multirow[t]{2}{*}{500} & $2 \rightarrow 5$ & 2 & & & & & 4 & & & & & & & \\
\hline & $3 \rightarrow 5$ & 2 & & & & 7 & & & & & & & & \\
\hline \multirow[t]{3}{*}{1500} & $2 \rightarrow 3$ & 2 & & & & & & & & & & 2 & & \\
\hline & $2 \rightarrow 3$ & 3 & 11 & & & & & & & & & & & \\
\hline & $3 \rightarrow 5$ & 1 & & & & & & & & & & & 3 & \\
\hline \multirow[t]{2}{*}{2000} & $2 \rightarrow 3$ & 3 & 12 & & & & & & & & & & & \\
\hline & $2 \rightarrow 4$ & 1 & & 3 & & & & & & & & & & \\
\hline \multirow[t]{2}{*}{3500} & $1 \rightarrow 3$ & 3 & 4 & & & & & & & & & & & \\
\hline & $2 \rightarrow 3$ & 3 & 11 & & & & & & & & & & & \\
\hline
\end{tabular}

As the general stable multi-objective programming model is presented, it is a fourobjective problem of complex integers whose objective functions conflict. Multi-criteria measurement is used to solve models with conflicting OFs. According to this technique, stated in the literature review section, first, by considering each objective function separately and solving the problem of two or more objectives, we obtain the optimal answer to each objective function separately. Four models have been used to further analyse the objectives because of the simultaneous significance of four general loss goals in the production system and the supply chain and customer satisfaction:

- $\quad$ The first model:

The model involves the objective function of minimizing overall losses in the production system and supply chain while considering the specific limitations of this objective.

- $\quad$ The second model: 
This model involves maximizing customer satisfaction by minimizing the maximum number of deficiencies among all customer points and in all periods by considering the specific constraints of the model.

- $\quad$ The third model:

The model is an integrated objective function obtained from the standard combination of the deviation of the first and second $\mathrm{OF}$ from the optimal value available to them by considering the constraints existing for both models. The $\omega$ value changes and accordingly, different multi-objective planning problems are proposed and solved. Figure 2 reveals a graphical representation of the equilibrium between Z2 and Z1 for various matters of $\omega$ starting from zero and ending with one.

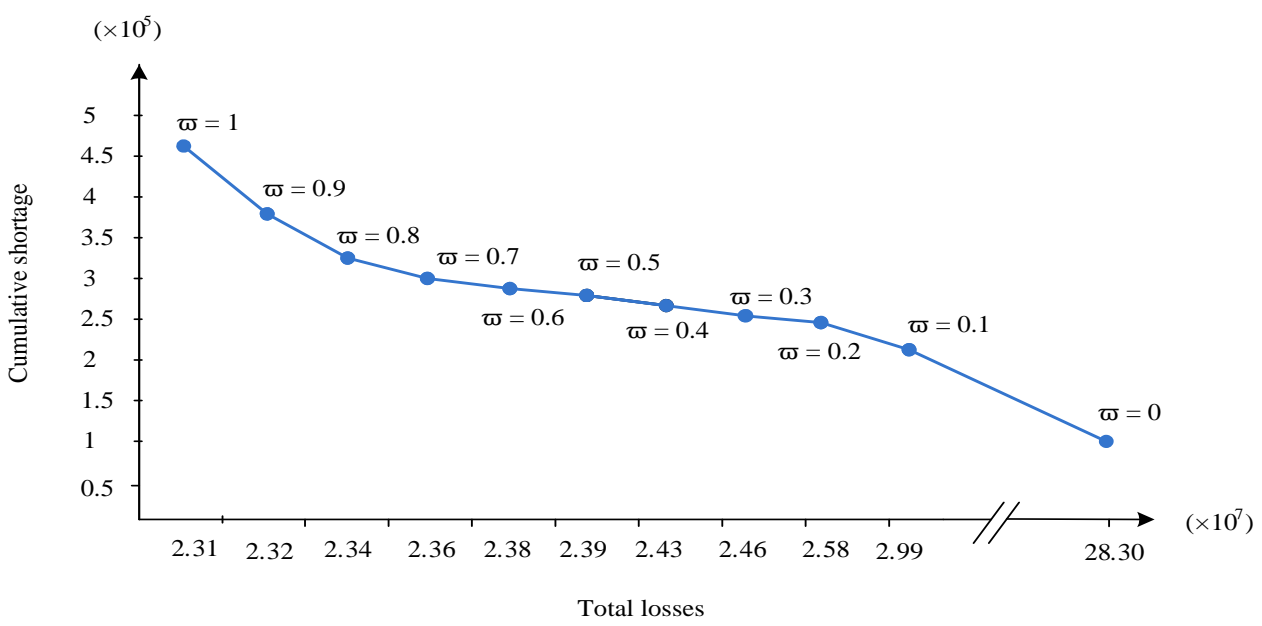

Figure 2. The loss of the supply chain against cumulative shortages.

Consider that when $\omega$ the value is equal to one, the model defined for the integrated objective function becomes the same as the model (1). When $\omega$ is zero, the model defined for the integrated objective function is the same as model (2). In model (1), the best value $\left(\mathrm{Z1}{ }^{*}\right)$, and in the model $(2)$, the worst value $(\mathrm{Z} 2 *) \omega$ is $\omega$ equal to zero.

In other words, if we consider one of the objective functions alone, it can sacrifice the other objective function. The comparisons show that if an integrated objective function model is defined, one can establish a relative balance between two opposing objective functions. Figure 3, which offers a Pareto efficiency curve, leaves the decision-maker free to select the answer he/she thinks is the best answer based on his/her relative preferences among the irrelevant answers.

In Figure 3, the sensitivity analysis is performed on the stability coefficient of the model for the single-objective models 1 and 2 and the integrated two-objective model. Figure 3a confirms that the value of the objective function $\mathrm{Z1}$ increases with an increase in the value of $\omega$ in model (2). Still, this increase in model (1) and the integrated model of the objective function compared to model (2) is not significant. To justify this, in model (2), there is no penalty for deviating from the unjustified answer.

Figure 4 presents the sensitivity analysis of model robustness versus the stability of the answer for the first objective function (Z1), obtained from solving the integrated objective function model. As was expected, the increase in $\omega$ leads to the rise in $\mathrm{Z1}$, but the slope of this increase decreases over time.

According to the results, solving 1 to 4 is impossible, as sales and services are zero. Solution 6, 3, and 9 have an intermediate level, which is determined as insufficient. On the contrary, solutions $5,2,10$, and 8 have the best performance expected. Other solutions were approximately $80 \%$ closer to the expected answer. When one compares the existing supply chain with the proposed supply chain in Table 5, one can see that operating costs are reduced by $20 \%$. In terms of the environmental effect, it is enhanced almost 20 times simultaneously with the level of service provided to the customer. These comparisons 
reveal that the network presented was firm in all performance objectives. Considering the explanations given, the results obtained from the hybrid approach for the four objective functions defined for the original model are shown in Table 6.

According to Table 6, the results of iteration 1 provide us with the best solutions.

(a) The total loss expected value

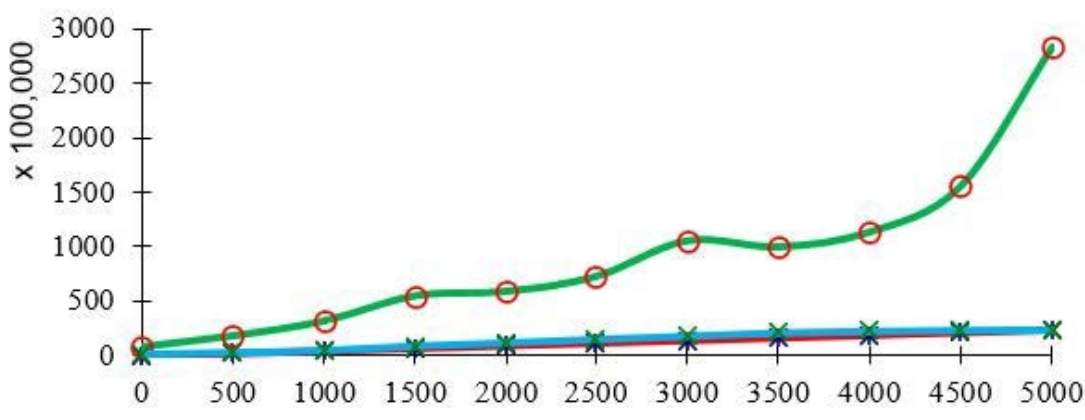

Omega

(b) The expected value of cumulative maximum deficit

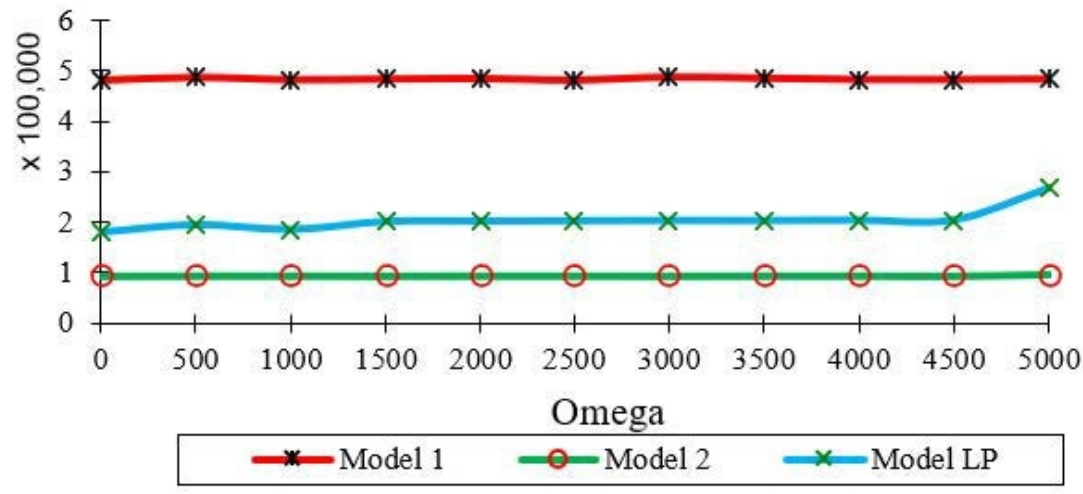

Figure 3. The equilibrium between model stability and Z1 and Z2 functions. (a) The total loss expected value; (b) The expected value of cumulative maximum deficit.

Expected value of total losses

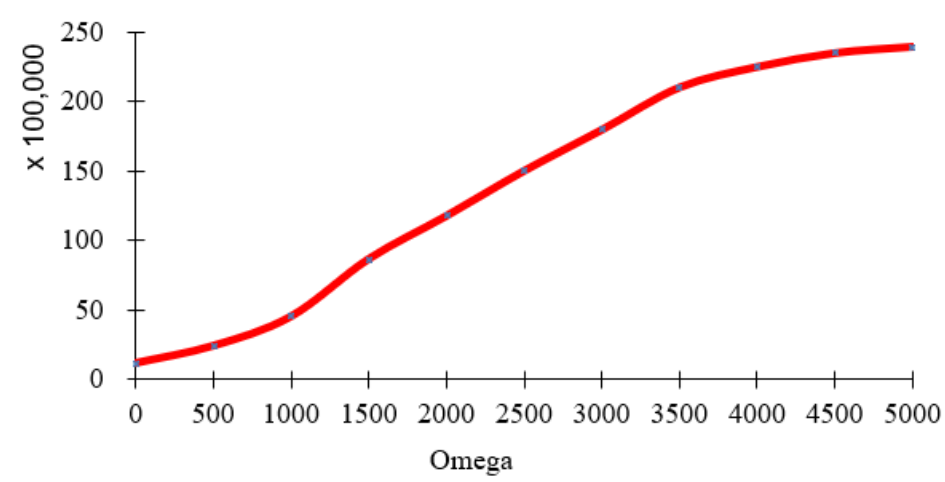

Figure 4. The relationship between model stability and Z1 value obtained from the integrated model. 
Table 5. The objective function components for ten iterations.

\begin{tabular}{|c|c|c|c|c|c|c|}
\hline Iteration & Time (S) & Total Cost & $\begin{array}{c}\text { Greenhouse } \\
\text { Gases Cost }\end{array}$ & $\begin{array}{c}\text { Transportation } \\
\text { Cost }\end{array}$ & Shortage Cost & $\begin{array}{c}\text { Fixed and } \\
\text { Operational Cost }\end{array}$ \\
\hline 1 & 123 & 992,805 & 263,960 & 155,490 & 18,135 & 424,180 \\
\hline 2 & 139 & 945,580 & 242,290 & 154,800 & 15,765 & 408,225 \\
\hline 3 & 180 & $963,829.4$ & 246,500 & 157,030 & 7229.4 & 423,960 \\
\hline 4 & 324 & 944,579 & 253,110 & 152,060 & 2974 & 407,805 \\
\hline 5 & 360 & 968,527 & 252,900 & 154,830 & 21,877 & 411,730 \\
\hline 6 & 346 & 967,735 & 244,840 & 156,350 & 15,765 & 423,200 \\
\hline 7 & 460 & 958,540 & 251,140 & 155,030 & 13,685 & 411,635 \\
\hline 8 & 2170 & 945,948 & 242,830 & 154,180 & 4048 & 418,470 \\
\hline 9 & 6410 & 934,048 & 239,610 & 150,340 & 8881 & 408,957 \\
\hline 10 & 7854 & 981,056 & 251,920 & 157,850 & 23,816 & 419,070 \\
\hline Expected Value & - & $960,264.7$ & 248,910 & 154,796 & $13,217.54$ & $41,5723.2$ \\
\hline $\begin{array}{l}\text { Standard } \\
\text { Deviation }\end{array}$ & - & $18,211.31$ & 7178.2805 & 2235.85 & 7213.927 & 6760.7712 \\
\hline
\end{tabular}

Table 6. The results of the integrated model objectives based on each iteration.

\begin{tabular}{ccccc}
\hline Iteration & OF 1 & OF 2 & OF 3 & OF 4 \\
\hline 1 & $1.3438 \times 10^{14}$ & $1.1292 \times 10^{11}$ & $9.2604 \times 10^{9}$ & 140,628 \\
2 & $3.7610 \times 10^{14}$ & $3.4441 \times 10^{11}$ & $5.6963 \times 10^{9}$ & 333,747 \\
3 & $3.7399 \times 10^{14}$ & $3.4251 \times 10^{11}$ & $5.7955 \times 10^{9}$ & 335,087 \\
4 & $3.7570 \times 10^{14}$ & $3.4357 \times 10^{11}$ & $5.7742 \times 10^{9}$ & 331,030 \\
5 & $3.7495 \times 10^{14}$ & $3.4303 \times 10^{11}$ & $5.6723 \times 10^{9}$ & 325,840 \\
6 & $3.7550 \times 10^{14}$ & $3.4394 \times 10^{11}$ & $5.6812 \times 10^{9}$ & 334,992 \\
7 & $3.7652 \times 10^{14}$ & $3.4473 \times 10^{11}$ & $5.7443 \times 10^{9}$ & 328,672 \\
8 & $3.7499 \times 10^{14}$ & $3.4343 \times 10^{11}$ & $5.7880 \times 10^{9}$ & 344,037 \\
9 & $3.7441 \times 10^{14}$ & $3.4221 \times 10^{11}$ & $5.6980 \times 10^{9}$ & 322,564 \\
\hline
\end{tabular}

\section{Conclusions and Discussions}

This research develops a multi-objective, multi-product MILP model for the four echelons of PPSC. The approaches used, while centrally integrating overall planning and supply chain decisions, have two basic steps: In the first step, significant pre-production processes such as the value and manner of the supply of raw materials from suppliers, logistics planning and raw material transportation, production rate determination, and labor management in manufacturing plants are examined. In the second step, with the implementation of the decisions in the first step, a decision is made about the value and manner of inventory maintenance, the weight and method of the distribution of goods to customers, and logistics planning. Decisions about the first step are all made according to predicted parameter values, and decisions about the second step are all based on the actual values of the parameters. To evaluate the efficiency and applicability of the research model, it was solved as a case study with various sensitivity analyses performed to validate the model. The computational results obtained from a real dataset reveal that the model can consider concepts such as customer satisfaction in an integrated manner and at the same time, with tactical production decisions. By introducing the idea of a perishable goods supply chain, the model presents the overall flexible production planning considering demand uncertainty. Moreover, the model shows how GGE and industrial waste management can overshadow program structures and presents realistic nonlinear functions for mitigation and shortage, using realistic models. These credible models create a clearer illustration of various future scenarios.

It is recommended that researchers consider integrating strategic decisions with tactical/operational decisions in future studies. For instance, the proposed models can only lead to savings up to a specific level in the discussion of industrial waste management and greenhouse gas emissions. More savings can be associated with strategic and macro decisions, including the construction of refining systems or technological upgrades of 
manufacturing processes. Additionally, other strategic decisions such as constructing new production plants and obtaining new suppliers should be considered.

Author Contributions: Conceptualization, F.Y. and I.M.-K.; methodology, S.G.; software, S.G.; validation, I.M.-K. and R.Č.; formal analysis, F.Y. and R.Č.; investigation, R.Č. and F.Y.; resources, S.G., and R.Č.; data curation, I.M.-K. and S.G.; writing-original draft preparation, F.Y. and S.G.; writingreview and editing, I.M.-K.; visualization, S.G.; supervision I.M.-K. All authors have read and agreed to the published version of the manuscript.

Funding: This research was funded by General Jonas Žemaitis Military Academy of Lithuania, as a part of the Study Support Project "Research on the Small State Logistics and Defence Technology Management".

Institutional Review Board Statement: Not applicable.

Informed Consent Statement: Not applicable.

Data Availability Statement: The data of this study are available from the authors upon request.

Conflicts of Interest: The authors declare no conflict of interest.

\section{References}

1. Biuki, M.; Kazemi, A.; Alinezhad, A. An integrated location-routing-inventory model for sustainable design of a perishable products supply chain network. J. Clean. Prod. 2020, 260, 120842. [CrossRef]

2. Simchi-Levi, D.; Kaminsky, P.; Simchi-Levi, E. Managing the Supply Chain: Definitive Guide; Tata McGraw-Hill Education; McGraw Hill: London, UK, 2004.

3. Hendalianpour, A.; Fakhrabadi, M.; Zhang, X.; Feylizadeh, M.R.; Gheisari, M.; Liu, P.; Ashktorab, N. Hybrid Model of IVFRNBWM and Robust Goal Programming in Agile and Flexible Supply Chain, a Case Study: Automobile Industry. IEEE Access 2019, 7,71481-71492. [CrossRef]

4. Vakili, R.; Shirazi, M.A.; Gitinavard, H. Multi-echelon green open-location-routing problem: A robust-based stochastic optimization approach. Sci. Iran. 2020, 28, 985-1000. [CrossRef]

5. Sahebi, I.G.; Masoomi, B.; Ghorbani, S. Expert oriented approach for analyzing the blockchain adoption barriers in humanitarian supply chain. Technol. Soc. 2020, 63, 101427. [CrossRef]

6. Arab, A.; Sahebi, I.G.; Modarresi, M.; Ajalli, M. Grey DEMATEL approach for ranking the KSFs of environmental management system implementation (ISO 14001). Calitatea 2017, 18, 115.

7. Ferreira, F.A.F.; Meidute-Kavaliauskienè, I. Toward a sustainable supply experience using single-valued neutrosophic sets and fuzzy cognitive maps. Ann. Oper. Res. 2019, 1-22. [CrossRef]

8. De Keizer, M.; Akkerman, R.; Grunow, M.; Bloemhof, J.M.; Haijema, R.; van der Vorst, J.G. Logistics network design for perishable products with heterogeneous quality decay. Eur. J. Oper. Res. 2017, 262, 535-549. [CrossRef]

9. Meidute-Kavaliauskiene, I.; Davidaviciene, V.; Ghorbani, S.; Sahebi, I. Optimal Allocation of Gas Resources to Different Consumption Sectors Using Multi-Objective Goal Programming. Sustainability 2021, 13, 5663. [CrossRef]

10. Sadeghi Moghadam, M.; Ghasemian Sahebi, I. A Mathematical Model to Improve the Quality of Demand Responding in Emergency Medical Centers in a Humanitarian Supply chain. Mod. Res. Decis. Mak. 2018, 3, 217-242.

11. Sahebi, I.G.; Masoomi, B.; Ghorbani, S.; Uslu, T. Scenario-based designing of closed-loop supply chain with uncertainty in returned products. Decis. Sci. Lett. 2019, 8, 505-518. [CrossRef]

12. Arab, A.; Sahebi, I.G.; Alavi, S.A. Assessing the Key Success Factors of Knowledge Management Adoption in Supply Chain. Int. J. Acad. Res. Bus. Soc. Sci. 2017, 7, 2222-6990. [CrossRef]

13. Moghadam, M.S.; Sahebi, I.G. Humanitarian Supply Chain: From Theory to Practice, 1st ed.; University of Tehran Press: Tehran, Iran, 2021.

14. Puskás, E.; Budai, Á.; Bohács, G. Optimization of a physical internet based supply chain using reinforcement learning. Eur. Transp. Res. Rev. 2020, 12, 1-15. [CrossRef]

15. Rasi, R.E. A Cuckoo Search Algorithm Approach for Multi Objective Optimization in Reverse Logistics Network under Uncertainty Condition. Int. J. Suppl. Oper. Manag. 2018, 5, 66-80.

16. Pishvaee, M.S.; Rabbani, M. A graph theoretic-based heuristic algorithm for responsive supply chain network design with direct and indirect shipment. Adv. Eng. Softw. 2011, 42, 57-63. [CrossRef]

17. Rafie-Majd, Z.; Pasandideh, S.H.R.; Naderi, B. Modelling and solving the integrated inventory-location-routing problem in a multi-period and multi-perishable product supply chain with uncertainty: Lagrangian relaxation algorithm. Comput. Chem. Eng. 2018, 109, 9-22. [CrossRef]

18. Dai, Z.; Aqlan, F.; Zheng, X.; Gao, K. A location-inventory supply chain network model using two heuristic algorithms for perishable products with fuzzy constraints. Comput. Ind. Eng. 2018, 119, 338-352. [CrossRef] 
19. Zhang, H.; Yang, K. Multi-Objective Optimization for Green Dual-Channel Supply Chain Network Design Considering Transportation Mode Selection. In Supply Chain and Logistics Management; IGI Global: Hershey, PA, USA, 2020; pp. $382-404$.

20. Rabbani, M.; Hosseini-Mokhallesun, S.A.A.; Ordibazar, A.H.; Farrokhi-Asl, H. A hybrid robust possibilistic approach for a sustainable supply chain location-allocation network design. Int. J. Syst. Sci. Oper. Logist. 2020, 7, 60-75. [CrossRef]

21. Baboli, A.; Fondrevelle, J.; Tavakkoli-Moghaddam, R.; Mehrabi, A. A replenishment policy based on joint optimization in a downstream pharmaceutical supply chain: Centralized vs. decentralized replenishment. Int. J. Adv. Manuf. Technol. 2011, 57, 367-378. [CrossRef]

22. Kelle, P.; Woosley, J.; Schneider, H. Pharmaceutical supply chain specifics and inventory solutions for a hospital case. Oper. Res. Health Care 2012, 1, 54-63. [CrossRef]

23. Uthayakumar, R.; Priyan, S. Pharmaceutical supply chain and inventory management strategies: Optimization for a pharmaceutical company and a hospital. Oper. Res. Health Care 2013, 2, 52-64. [CrossRef]

24. Mousazadeh, M.; Torabi, S.; Zahiri, B. A robust possibilistic programming approach for pharmaceutical supply chain network design. Comput. Chem. Eng. 2015, 82, 115-128. [CrossRef]

25. Zahiri, B.; Zhuang, J.; Mohammadi, M. Toward an integrated sustainable-resilient supply chain: A pharmaceutical case study. Transp. Res. Part E Logist. Transp. Rev. 2017, 103, 109-142. [CrossRef]

26. Zahiri, B.; Jula, P.; Tavakkoli-Moghaddam, R. Design of a pharmaceutical supply chain network under uncertainty considering perishability and substitutability of products. Inf. Sci. 2018, 423, 257-283. [CrossRef]

27. Sabouhi, F.; Pishvaee, M.S.; Jabalameli, M.S. Resilient supply chain design under operational and disruption risks considering quantity discount: A case study of pharmaceutical supply chain. Comput. Ind. Eng. 2018, 126, 657-672. [CrossRef]

28. Singh, S.K.; Goh, M. Multi-objective mixed integer programming and an application in a pharmaceutical supply chain. Int. J. Prod. Res. 2019, 57, 1214-1237. [CrossRef]

29. Savadkoohi, E.; Mousazadeh, M.; Torabi, S.A. A possibilistic location-inventory model for multi-period perishable pharmaceutical supply chain network design. Chem. Eng. Res. Des. 2018, 138, 490-505. [CrossRef]

30. Nasrollahi, M.; Razmi, J. A mathematical model for designing an integrated pharmaceutical supply chain with maximum expected coverage under uncertainty. Oper. Res. 2021, 21, 525-552. [CrossRef]

31. Akbarpour, M.; Torabi, S.A.; Ghavamifar, A. Designing an integrated pharmaceutical relief chain network under demand uncertainty. Transp. Res. Part E Logist. Transp. Rev. 2020, 136, 101867. [CrossRef]

32. Kovačić, D.; Hontoria, E.; Ros-McDonnell, L.; Bogataj, M. Location and lead-time perturbations in multi-level assembly systems of perishable goods in Spanish baby food logistics. Cent. Eur. J. Oper. Res. 2015, 23, 607-623. [CrossRef]

33. Sahebi, I.G.; Toufighi, S.P.; Karakaya, G.; Ghorbani, S. An intuitive fuzzy approach for evaluating financial resiliency of supply chain. OPSEARCH 2021, 1-22. [CrossRef]

34. Sahebi, I.G.; Mosayebi, A.; Masoomi, B.; Marandi, F. Modeling the enablers for blockchain technology adoption in renewable energy supply chain. Technol. Soc. 2022, 68, 101871. [CrossRef]

35. Li, L.; Dababneh, F.; Zhao, J. Cost-effective supply chain for electric vehicle battery remanufacturing. Appl. Energy 2018, 226, 277-286. [CrossRef]

36. He, L.; Chen, Y.; Li, J. A three-level framework for balancing the tradeoffs among the energy, water, and air-emission implications within the life-cycle shale gas supply chains. Res. Conserv. Recycl. 2018, 133, 206-228. [CrossRef]

37. Saif-Eddine, A.S.; El-Beheiry, M.M.; El-Kharbotly, A.K. An improved genetic algorithm for optimizing total supply chain cost in inventory location routing problem. Ain Shams Eng. J. 2019, 10, 63-76. [CrossRef]

38. Asim, Z.; Jalil, S.A.; Javaid, S. An uncertain model for integrated production-transportation closed-loop supply chain network with cost reliability. Sustain. Prod. Consum. 2019, 17, 298-310. [CrossRef]

39. Dinh, T.T.A.; Liu, R.; Zhang, M.; Chen, G.; Ooi, B.C.; Wang, J. Untangling Blockchain: A Data Processing View of Blockchain Systems. IEEE Trans. Knowl. Data Eng. 2018, 30, 1366-1385. [CrossRef]

40. Wang, C.-N.; Nhieu, N.-L.; Chung, Y.-C.; Pham, H.-T. Multi-Objective Optimization Models for Sustainable Perishable Intermodal Multi-Product Networks with Delivery Time Window. Mathematics 2021, 9, 379. [CrossRef]

41. Rahmaniani, R.; Crainic, T.G.; Gendreau, M.; Rei, W. The Benders decomposition algorithm: A literature review. Eur. J. Oper. Res. 2017, 259, 801-817. [CrossRef]

42. Tarvin, D.A.; Wood, R.K.; Newman, A.M. Benders decomposition: Solving binary master problems by enumeration. Oper. Res. Lett. 2016, 44, 80-85. [CrossRef] 